\title{
Novel biliary drainage of a choledochojejunal anastomotic stenosis using a double- balloon endoscope and forward-viewing endoscopic ultrasound
}
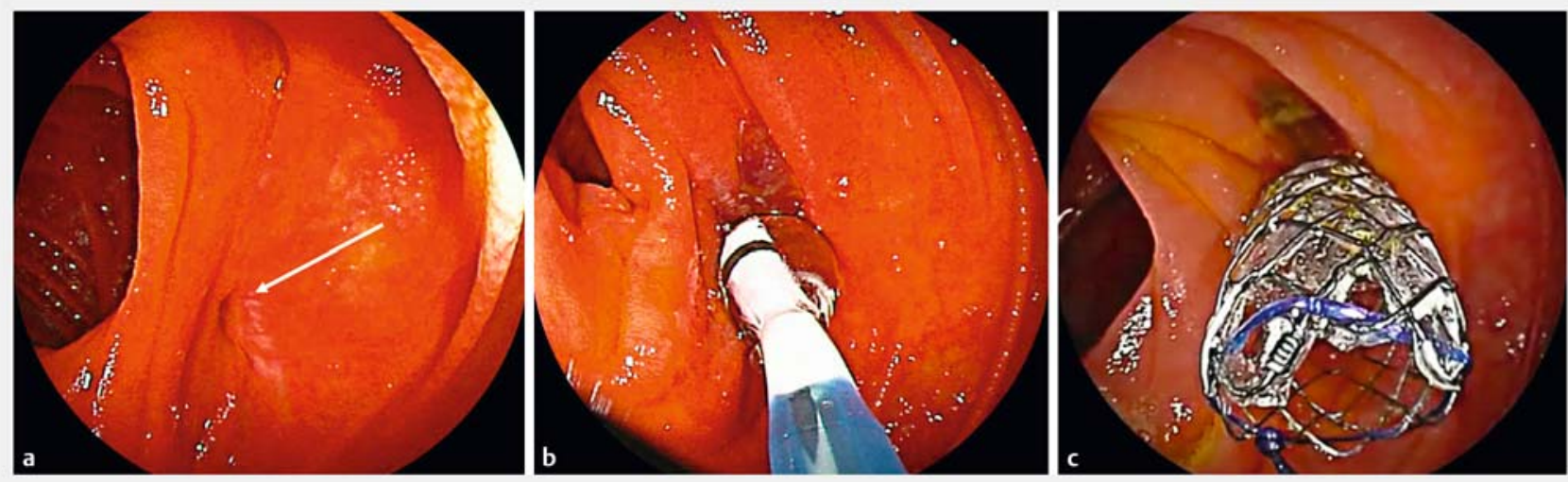

- Fig. 1 Views during double-balloon endoscopy of the choledochojejunal anastomosis of the anterior branch showing: a the choledochojejunal anastomotic stenosis (arrow); b balloon dilation; c deployment of the metal stent.

Balloon-assisted enteroscopy (BAE) is used to drain biliary obstructions caused by choledochojejunal anastomotic stenosis (CJS) after digestive tract reconstruction. Endoscopic ultrasound-guided biliary drainage (EUS-BD) is an alternative when scope insertion to the anastomotic site by BAE is difficult [ $1-4]$. However, EUS-BD is also difficult in post-left lobectomy patients generally. Here, we report a novel method of internal drainage that combined double-balloon endoscopy (DBE) and forward-viewing EUS for a posterior branch CJS following Roux-en-Y reconstruction.

A 70-year-old man developed obstructive cholangitis after extended left lobectomy and Roux-en-Y reconstruction for hilar cholangiocarcinoma. Anastomotic drainage by DBE was attempted for suspected CJS. The anterior and posterior branches had been anastomosed independently to the jejunum. The anterior branch anastomotic site was easily dilated (\ Fig.1). However, a complete posterior-branch CJS prevented guidewire insertion ( $\triangleright$ Fig. 2 ). A percutaneous transhepatic biliary drainage antegrade break-through for posterior-branch CJS also failed. DBE to the posterior-branch CJS through the anastomotic site was re-
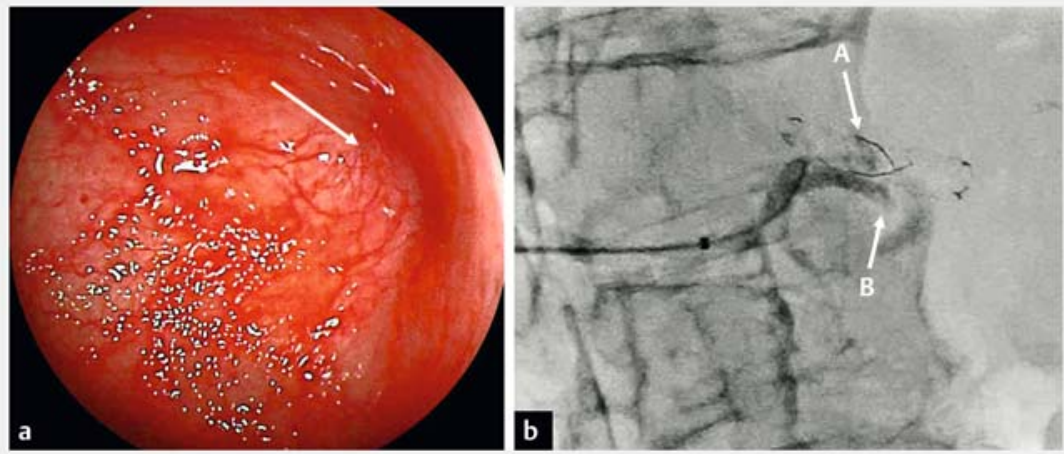

- Fig. 2 Complete obstruction of the choledochojejunal anastomosis of the posterior branch is shown on: a endoscopic view; b fluoroscopic view with the deployed stent for the choledochojejunal anastomotic stenosis of the anterior branch (arrow A) and the choledochojejunal anastomotic stenosis of the posterior branch (arrow B) both visible.

attempted but failed again, prompting an attempted EUS-BD with forwardviewing EUS from the anastomotic site. First, a guidewire (Revowave $\alpha$; PIOLAX, Yokohama, Japan) was inserted through the DBE forceps channel to the jejunum near the anastomotic site before the double-balloon endoscope was removed ( $\vee$ Video 1$)$. Next, the guidewire was inserted into the EUS forceps port for supported insertion, which enabled intubation near the posterior-branch CJS
( Fig.3). The posterior segmental branch was identified on forward-viewing EUS near the anastomotic site and punctured with a 19G fine-needle aspiration (FNA) needle, followed by cholangiography and guidewire placement (Visiglide2; Olympus, Tokyo, Japan) into the peripheral biliary duct according to the puncture angle. After balloon dilation of the anastomotic site (REN, 4-mm wide; Kaneka Medix Corporation, Tokyo, Japan), a fully covered self-expanding metal stent 


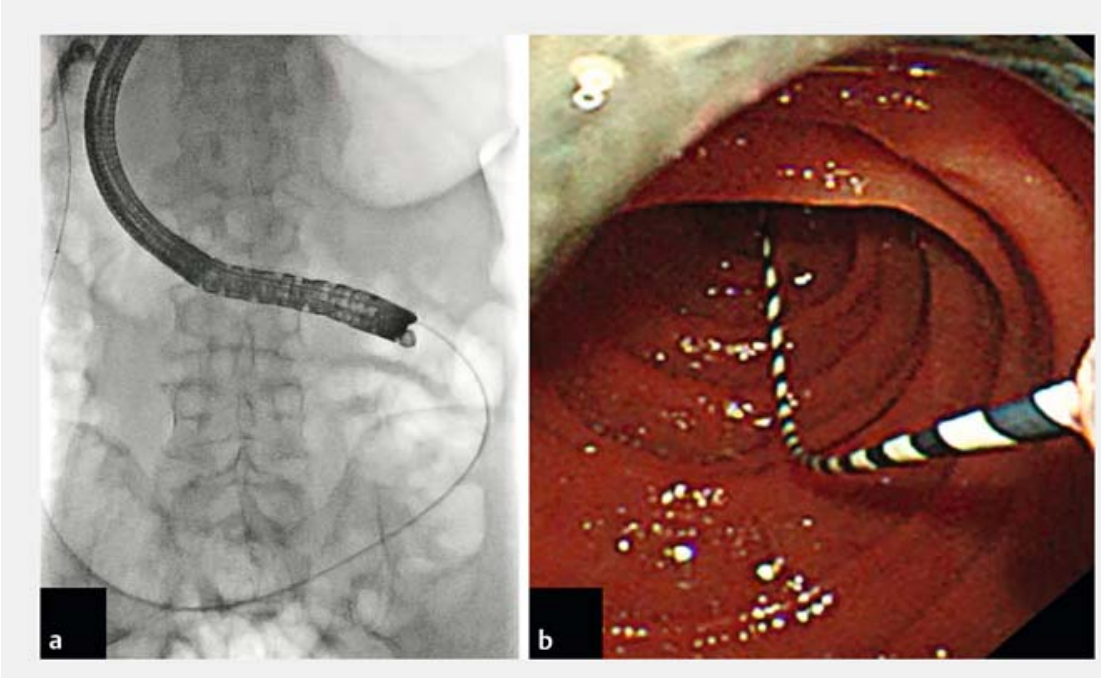

- Fig. 3 Insertion of the forward-viewing endoscopic ultrasound using the guidewire placed near the choledochojejunostomy by the double-balloon endoscope is seen on: a fluoroscopic image; b endoscopic view.

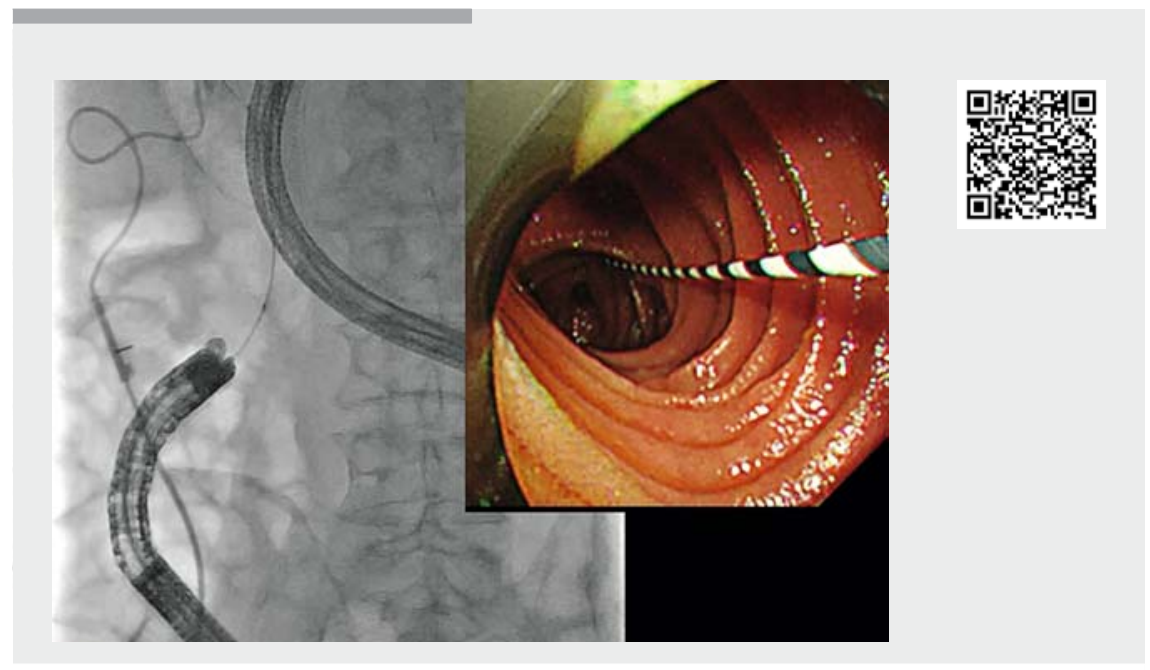

Video 1 A novel method is demonstrated for biliary drainage of a choledochojejunal anastomotic stenosis using a double-balloon endoscope and forward-viewing endoscopic ultrasound.
(SEMS; $8 \times 60-\mathrm{mm}$ fully covered SEMS; $X$ suit NIR; Olympus) was placed in the posterior segmental branch via the jejunal fistula site ( Fig. 4 and $>$ Fig.5). The patient's jaundice and inflammation improved without complications.

Endoscopy_UCTN_Code_TTT_1AS_2AD

Acknowledgments

This work was supported in part by The National Cancer Center Research and Development Fund (31-A-13).

\section{Competing interests}

The authors declare that they have no conflict of interest.

The authors

Kosuke Maehara', Susumu Hijioka', Taku Sakamoto ${ }^{2}$, Yuta Maruki ${ }^{1}$, Kiichi Tamada ${ }^{3}$, Takuji Okusaka', Yutaka Saito ${ }^{2}$

1 Department of Hepatobiliary and Pancreatic Oncology, National Cancer Center Hospital, Tokyo, Japan

2 Endoscopy Division, National Cancer Center Hospital, Tokyo, Japan

3 Department of Medicine, Division of Gastroenterology, Jichi Medical University, Tochigi, Japan

\section{Corresponding author}

\section{Susumu Hijioka, MD}

Department of Hepatobiliary and Pancreatic Oncology, National Cancer Center Hospital, 5-1-1 Tsukiji, Chuo-ku, Tokyo, Japan Fax: +81-3-35423815

shijioka@ncc.go.jp

References

[1] House MG, Cameron JL, Schulick RD et al. Incidence and outcome of biliary strictures after pancreaticoduodenectomy. Ann Surg 2006; 243: 571-576; discussion 576-578

[2] Bonnel DH, Fingerhut AL. Percutaneous transhepatic balloon dilatation of benign bilioenteric strictures: long-term results in 110 patients. Am J Surg 2012; 203: 675-683 

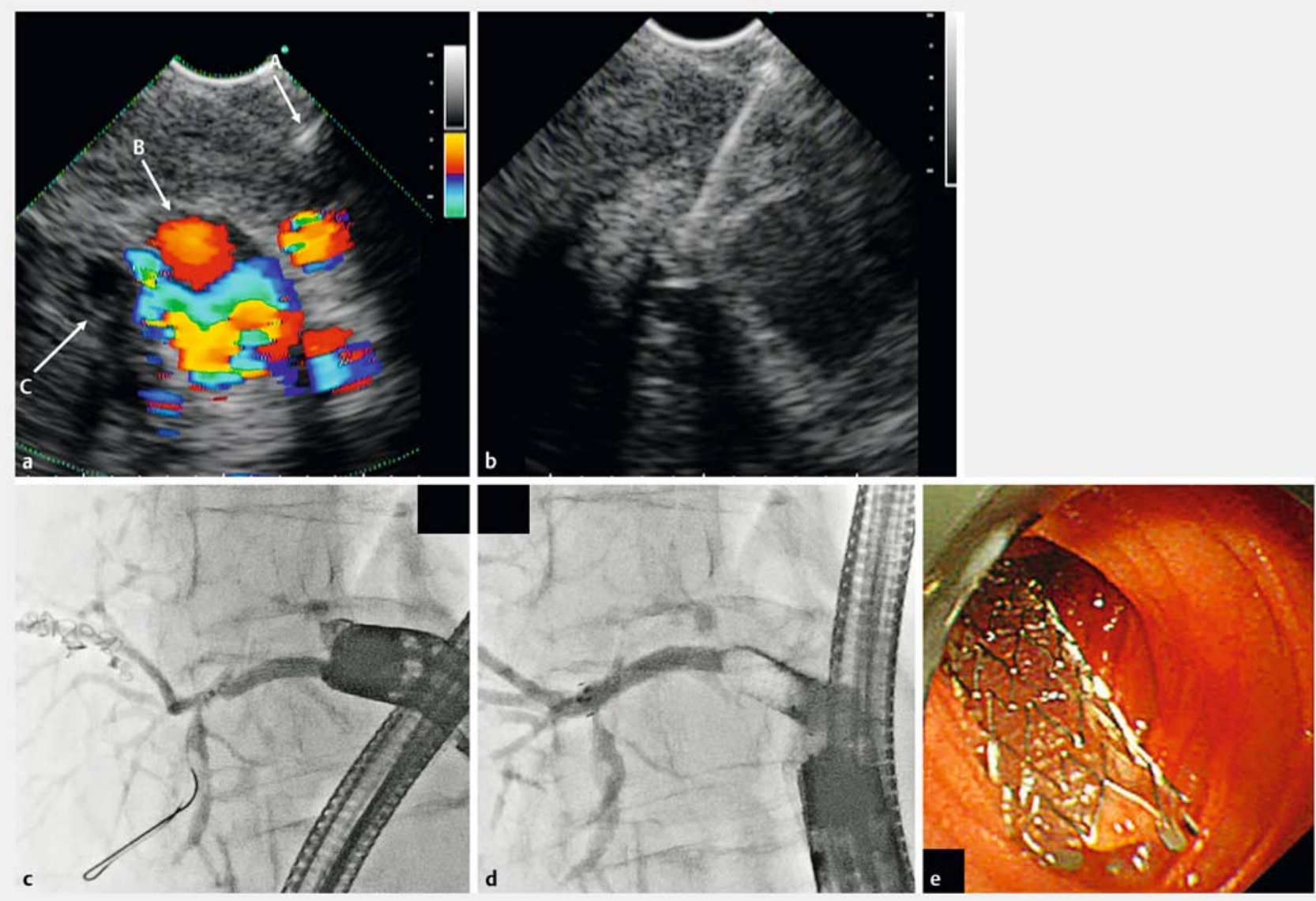

- Fig. 4 Images during forward-viewing endoscopic ultrasound (EUS)-guided posterior biliary branch drainage showing: a on an EUS image obtained near the choledochojejunostomy, the puncture needle (arrow A), the portal vein (arrow B), and the posterior biliary branch (arrow C); b puncture of the posterior biliary branch seen by EUS; $\mathbf{c}$ balloon dilation of the puncture route seen fluoroscopically; $\mathbf{d}$ fluoroscopic view of the metal stent from the posterior branch to the jejunum; e endoscopic view of the deployed stent.

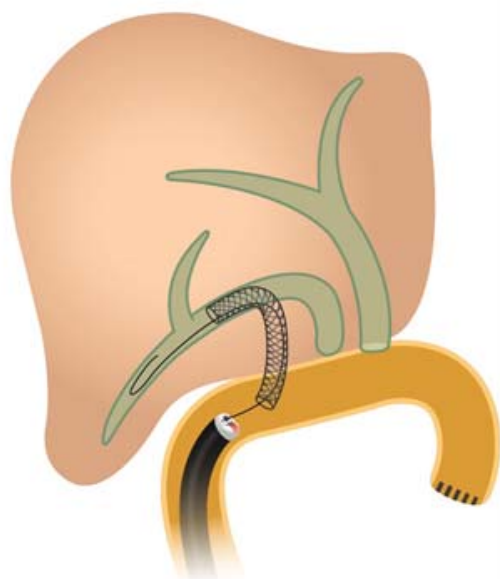

- Fig. 5 Schema of biliary drainage for a choledochojejunal anastomotic stenosis using a double-balloon endoscope and forward-viewing endoscopic ultrasound.
[3] Yamada A, Kogure H, Nakai Y et al. Performance of a new short-type double-balloon endoscope with advanced force transmission and adaptive bending for pancreaticobiliary intervention in patients with surgically altered anatomy: A propensity-matched analysis. Dig Endosc 2019; 31: 86-93

[4] Sato T, Kogure H, Nakai Y et al. Double-balloon endoscopy-assisted treatment of hepaticojejunostomy anastomotic strictures and predictive factors for treatment success. Surg Endosc 2020; 34: 1612-1620

Bibliography

Endoscopy 2021; 53: E242-E244

DOI 10.1055/a-1247-4469

ISSN 0013-726X

published online 23.9.2020

(c) 2020. Thieme. All rights reserved.

Georg Thieme Verlag KG, Rüdigerstraße 14,

70469 Stuttgart, Germany

\section{ENDOSCOPY E-VIDEOS}

https://eref.thieme.de/e-videos

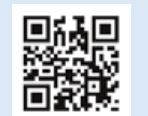

Endoscopy E-Videos is a free access online section, reporting on interesting cases and new techniques in gastroenterological endoscopy. All papers include a high quality video and all contributions are freely accessible online.

This section has its own submission website at

https://mc.manuscriptcentral.com/e-videos 